\title{
Visibility concept in road lighting
}

\author{
M. Zalesińska \\ Poznan University of Technology, \\ Institute of Electrical Engineering and Electronics, Poland
}

\begin{abstract}
A major purpose of road lighting is to increase the visibility for drivers and other roadway users. The visibility of a target depends on observer age and visual characteristics, observer duration, size of target, luminance of the target, luminance of the background, contrast polarity, exposure time, magnitude of the disability glare, and adaptation. A visibility formula was described by Adrian in 1989 and applied with Visibility Levels in North America as a quality criterion. According to procedures described in ANSI/IESNA RP-8-00: American National Standard Practice for Roadway Lighting the visibility of the target can be calculated when the target luminance, background luminance and veiling luminance in calculation methods are given. In European countries this criterion is still investigated as a new concept.

Keywords: road lighting, visibility level, small target visibility, road lighting standards.
\end{abstract}

\section{Introduction}

Road lighting has significant impact on road traffic comfort and safety. All participants of the traffic, vehicle drivers, cyclists and pedestrians alike, should benefit from vision conditions that facilitate the completion of visual tasks. The entire road along with its background should be well visible at all times. Cyclists and pedestrians alike should see all obstacles in their way and should be able to correctly identify the intentions of other traffic participants. The visual reliability of drivers should be suitably high to allow them to spot, quickly enough, pedestrians, cyclists and any obstacles present in their traffic lane, as well as road signs and information boards in its immediate background, in order to reduce the likelihood of dangerous situations or traffic accidents. Even though the attempts to identify direct relation between quantitative and quality parameters of road 
lighting, such as road luminance (illuminance), longitudinal uniformity, surround ratio, glare limit and road accident ratio have failed so far, numerous research projects have confirmed a significantly lower number of accidents on illuminated roads in relation to conditions where there is no fixed road illumination, the illumination is off or its design is faulty. Studies have shown that the accident rate is 1.5 to 2 times higher during the night-time than in daylight. In the case of the fatal accidents the rate is three times higher in darkness as in daylight. In general, construction of road lighting is found to reduce night-time accidents by $20-40 \%$. Based on several studies, the mean accident reducing effect in darkness is found to be about $30 \%$ for all injury accidents, $60 \%$ for all fatal accidents, $45 \%$ for pedestrian accidents, $35 \%$ for injury accidents at rural junctions, and $50 \%$ for injury accidents on motorways [5]. A great deal of investment and operating costs of road lighting equipment translate to savings to the society, as many accidents are effectively prevented.

\section{Visibility of targets in illuminated roads}

A driver can spot an object in the road or in its background only if the contrast the object creates with the background (the road or its background) is above the threshold value of the contrast. If the object's luminance is higher than the luminance of the background the contrast is positive, otherwise the contrast is negative - which is most often the case with road lighting.

The difficulty of spotting obstacles in the road depends on the following factors:

- the contrast between the luminance of the object and its immediate visual background,

- the general level of adaptation of that portion of the retina of the eye concerned with the object,

- observer duration on road,

- the size, shape of the object,

- disability glare - the amount of veiling luminance entering the eye,

- transient adaptation - the difference in eye adaptation between successive eye movements,

- the background complexity and the dynamics of traffic,

- visual capability of drivers.

Numerous research projects of the past 70 years aimed to identify the criterion for evaluation of visibility of obstacles in the road. On the basis of Blackwell's laboratory research, the International Commission on Illumination (CIE) introduced in 1972 the Visibility Level (VL) (eqn (1)) defined as the relation of current contrast of a reference object (a disc of angular diameter of 4 minutes) to background, to the object's threshold contrast in threshold conditions, with the same background luminance [4].

$$
V L=\frac{C}{C_{t h}}=\frac{\Delta L}{\Delta L_{t h}}
$$


where: $\mathrm{C}$ is the actual contrast and $\mathrm{C}_{\mathrm{th}}$ is threshold contrast and $\Delta \mathrm{L}$ is the actual luminance difference in $\mathrm{cd} / \mathrm{m}^{2}, \Delta \mathrm{L}_{\mathrm{th}}$ is threshold luminance difference in $\mathrm{cd} / \mathrm{m}^{2}$.

Still, the direct application of formula (1) to calculate the Visibility Level in the road proved virtually impossible, as the driver's visual task differed from the relative task recommended by CIE [4] either in terms of the size and shape of objects used in the experiment, or in terms of criteria used for measuring the task's performance. Adrian's [1] research at the end of 1970's finally led to a calculation model of Visibility Level in the road. Currently, Adrian's formula is the basis for Small Target Visibility (STV) criterion. Apart from illuminance and luminance, STV is the third criterion employed when designing road lighting in USA. In Europe countries Small Target Visibility criterion is still investigated as a new concept.

\section{Night-time visibility assessment}

\subsection{Adrian's calculation model}

The visibility calculation model presented by Adrian [1] draws from laboratory research by Blackwell [3] and Aulthorn [2]. The calculation of threshold luminance difference $\left(\Delta \mathrm{L}_{\mathrm{th}}\right)$ of the object and background was based on two laws: Ricc's and Weber's. Adrian introduced two auxiliary functions: the luminous flux function determines perception, characteristic for the Riccoprocess, and luminance function L, reflecting Weber's law [1]:

$$
\Delta \mathrm{L}_{\mathrm{th}}=2.6 \cdot\left(\frac{\Phi^{\frac{1}{2}}}{\alpha}+\mathrm{L}^{\frac{1}{2}}\right)^{2}
$$

where: $\alpha$ - is the angular size of target in minutes of arc.

Moreover, the basic formula (eqn (2)) was extended by Adrian with factors that take into account the impact of the observer's age - AF, object observation time - TF and contract polarization $\mathrm{F}_{\mathrm{CP}}$ on the visibility of targets in an illuminated road (eqn (3), (4), (5)):

$$
\mathrm{AF}=\frac{\left(\mathrm{Age}-\mathrm{A}_{\mathrm{a}}\right)}{\mathrm{A}_{\mathrm{b}}}+\mathrm{A}_{\mathrm{c}}
$$

where: $A_{a}, A_{b}, A_{c}$ - constants dependent on the age and presented in [1],

$$
\mathrm{TF}=\frac{\mathrm{a}\left(\alpha, \mathrm{L}_{\mathrm{b}}\right)+\mathrm{t}}{\mathrm{t}}
$$


where: $t$ - observation time, $a\left(\alpha, L_{b}\right)$-function of target size and luminance of background,

$$
\mathrm{F}_{\mathrm{CP}}=\frac{\Delta \mathrm{L}_{\text {neg }}}{\Delta \mathrm{L}_{\text {pos }}}
$$

where: $\Delta \mathrm{L}_{\text {neg }}, \Delta \mathrm{L}_{\text {pos }}$ - luminance difference threshold for negative positive contrasts.

The presence of glare sources in the visual field of drivers impair their vision and results in a necessary increase in $\Delta \mathrm{L}_{\text {th }}$ to keep targets visible. The impact of glare hindering the driver's vision is taken into account by means of veiling luminance $\left(\mathrm{L}_{\mathrm{V}}\right)$ calculated on the basis of the classic Stiles-Holladay formula [9]:

$$
L_{v}=k \cdot \sum_{i=1}^{n} \frac{E_{\text {glare }_{i}}}{\Theta_{i}^{2}}
$$

where: $\mathrm{k}$ - constant dependent on the age, $\mathrm{E}_{\text {glare }}$ - illuminance at the eye due to the glare light in lux, $\Theta$ - the angel between the direction of glare source and the direction of the target in degrees.

In the case of glare the adaptation luminance $\left(\mathrm{L}_{\mathrm{a}}\right)$ around location of the target on the retina is consequently composed of the background luminance $\left(\mathrm{L}_{\mathrm{b}}\right)$ and veiling luminance $\left(L_{V}\right)$,

$$
L_{a}=L_{b}+L_{v}
$$

The threshold value of the difference of luminance of the object and background calculated with the above dependences and the current difference of luminance of the object and the background are components of the Visibility Level (VL) as identified by CIE (see eqn (1)).

\subsection{Small target visibility (STV)}

The American Standard Practice [10] includes three criteria for designing continuous lighting systems for roadways. These are illuminance, luminance, and Small Target Visibility. Illuminance (STV) based design is a simple design approach, which has been historically used in roadway lighting. It calculates the amount of light on the roadway surface. Luminance based design calculates the amount of light directed toward the driver and predicts the luminance of the roadway. Small Target Visibility is a visibility metric, which is used to determine the visibility of an array of targets on the roadway. STV includes the calculation following factors:

- the luminance of the targets,

- the luminance of the immediate background, 
- the adaptation level of the adjacent surroundings,

- $\quad$ the disability glare.

Target luminance $\left(\mathrm{L}_{\mathrm{t}}\right)$ is calculated for point at the centre of Lambertian Target and veiling luminance is calculated on the basis of the classic StilesHolladay formula (eqn (6)).

Background luminance $\left(\mathrm{L}_{\mathrm{b}}\right)$ is determined as the arithmetic average value of two background luminance $\left(\mathrm{L}_{\mathrm{b} 1}\right)$ and $\left(\mathrm{L}_{\mathrm{b} 2}\right)$. Background luminance $\left(\mathrm{L}_{\mathrm{b} 1}\right)$ is calculated at a point on the pavement adjacent to the centre of the bottom of the target, that is, the target's position on the roadway. $\mathrm{L}_{\mathrm{b} 2}$ is calculated at a point on the pavement 11.77 meters beyond the target, at a point on a line projected from the observer's point of view through the point at the centre of the top of the target (fig. 1).

a)

b)
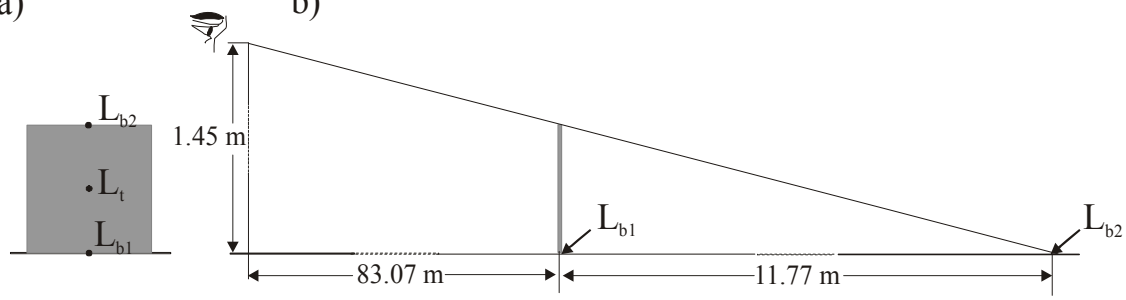

Figure 1: Luminance of target and background location on the pavement: a) front seeing, b) side seeing (not in scale).

The Visibility Level (VL) is calculated step-by-step basis on background luminance $\left(\mathrm{L}_{\mathrm{b}}\right)$ target luminance $\left(\mathrm{L}_{\mathrm{t}}\right)$ and several intermediate functions using the adaptation luminance $\left(\mathrm{L}_{\mathrm{a}}\right)$ and angular size of object $(\mathrm{A}=$ const $=7.45$ minutes $)$ (eqn: (8)-(32)).

Step 1: Determination of the sensitivity of the visual system as a function of adaptation luminance - functions $\mathrm{F}$ and $\mathrm{L}$. This is done by using one of three equations depending on the value of adaptation luminance.

If $\mathrm{La} \geq 0.6$

$$
\begin{gathered}
F=\left[\log _{10}\left(4.2841 \cdot L_{a}^{0.1556}\right)+\left(0.1684 \cdot L_{a}^{0.5867}\right)\right]^{2} \\
L=\left(0.05946 \cdot L_{a}^{0.466}\right)^{2}
\end{gathered}
$$

If $\mathrm{La} \geq 0.00418$ and $\mathrm{La}<0.6$

$$
\begin{gathered}
F=10\left\{2 \cdot\left[\left(0.0866 \cdot\left(\log _{10}\left(L_{a}\right)\right)^{2}+\left(0,3372 \cdot \log _{10}\left(L_{a}\right)\right)-0.072\right)\right]\right\} \\
L=10^{\left[2 \cdot\left(0.319 \cdot \log _{10}\left(L_{a}\right)-1.256\right)\right]}
\end{gathered}
$$


164 Lighting in Engineering, Architecture and the Environment

If La $<0.00418$

$$
\begin{gathered}
F=10^{\left(0.346 \cdot\left(\log _{10}\left(\mathrm{~L}_{a}\right)+0.056\right)\right.} \\
L=10^{\left[0.0454 \cdot\left(\log _{10}\left(L_{a}\right)\right)^{2}+1.055 \cdot \log _{10}\left(L_{a}\right)-1.782\right]}
\end{gathered}
$$

Step 2: Calculate intermediate functions: B, C, AA, AL, AZ, $\mathrm{DL}_{1}$.

$$
\begin{gathered}
B=\log _{10}(A)+0.523 \\
C=\log _{10}\left(L_{a}\right)+6 \\
A A=0.360-\frac{0.0972 \cdot B^{2}}{B^{2}-(2.513 \cdot B)+2.789} \\
A L=0.355-\frac{0.1217 \cdot C^{2}}{C^{2}-10.40 \cdot C+52.28} \\
A Z=\sqrt{\frac{(A A)^{2}+(A L)^{2}}{2.1}} \\
D L_{1}=2.6\left[\frac{\sqrt{F}}{A}+\sqrt{L}\right]^{2}
\end{gathered}
$$

Step 3: Calculate negative contrast factor (FCP) based on intermediate functions: $\mathrm{M}$ and TGB.

$$
\begin{aligned}
& \text { If }-2.4<\log _{10}(\mathrm{La})<-1 \\
& \qquad M=10^{-10^{-\left[0.075 \cdot\left(\log _{10}\left(L_{a}\right)+1\right)^{2}+0.0245\right]}}
\end{aligned}
$$

If $\log _{10}(\mathrm{La}) \geq-1$

$$
\begin{aligned}
& M=10^{-10^{-\left[0.125 \cdot\left(\log _{10}\left(L_{a}\right)+1\right)^{2}+0.0245\right]}} \\
& T G B=-0.6 \cdot\left(L_{a}\right)^{-0.1488}
\end{aligned}
$$




$$
F C P=1-\left[\frac{(M) \cdot(A)^{T G B}}{1.2 \cdot\left(D L_{1}\right)(A Z+2)}\right]
$$

If $\log _{10}(\mathrm{La})<$ or $=-2.4$ then $\mathrm{FCP}=0.5$.

Step 4: Adjust $\mathrm{DL}_{1}$ in accordance with the observation time $(\mathrm{t})$, which in [10] is a constant -0.2 seconds.

$$
D L_{2}=D L_{1} \cdot \frac{A Z+t}{t}
$$

Step 5: Calculated the adjustment (FA) for the age of observer (TA), which in [10] is a constant - 60 years. For the age less than 64 years:

$$
\begin{gathered}
F A=\left[\frac{\left(T A-19^{2}\right)}{2160}\right]+0.99 \\
D L_{3}=D L_{2} \cdot F A
\end{gathered}
$$

Step 6: Calculate the adjustment if the target is darker then background.

$$
D L_{4}=D L_{3} \cdot F C P
$$

If $\mathrm{L}_{\mathrm{b}}<\mathrm{L}_{\mathrm{t}}$ then $\mathrm{DL}_{4}=\mathrm{DL}_{3}$.

Step 7: Calculate Visibility Level (VL).

$$
V L=\frac{L_{t}-L_{b}}{D L_{4}}
$$

Step 8: Visibility Level is calculated for all grid points (n) and then there is determined Relative Weighted VL (RWVL) and Average RWVL (ARWVL)

$$
\begin{gathered}
R W V L=10^{\{-0.1 \cdot V L \mid\}} \\
A R W V L=\frac{\sum_{i=1}^{n} R W V L_{i}}{n}
\end{gathered}
$$

Finally, STV is calculated.

$$
\text { STV=Weighted Average VL= }-10 \log _{10}(\text { ARWVL })
$$




\section{Simplifications and assumptions employed in Adrian's formula and in STV}

The Small Target Visibility criterion, based to a large extent on Adrian's [1] model, introduces far-reaching simplifications for the calculation of the Visibility Level, despite its clear method of evaluation. The road section considered during the calculation is free from other traffic participants and vehicles approach from the opposite direction, hence no glare caused by headlights of these vehicles. The driver's visual task is simple and consists in spotting an object in a specified location, aligned directly with the driver's eyesight. Under real conditions, the complexity and dynamics, combined with other traffic participants, significantly limit the visibility of obstacles in the road. Several question come to mind when analyzing the visibility criterion, concerning the calculation of background luminance and the driver's adaptation conditions:

- What makes up the background luminance of the object in the road? Is it arithmetic average from luminance on road surface where the object is located and luminance at the distance of $11.77 \mathrm{~m}$ behind the object, or is its average luminance for a specific road surface in the vicinity of the obstacle (see fig. 1)?

- What elements in the driver's field of vision specify its adaptation? Is it only the point's background luminance and veiling luminance generated by the source of glare (see eqn (7))? Undoubtedly, the driver's field of vision is much wider than the traffic lane itself. Apart from the road, it consists of its background on the left and right, visible landscape and a part of the sky.

- Would it not be necessary, for purposes of calculating road visibility, especially for roads located in centers of towns, to take into account transient adaptation taking place when shifting eyesight from the road to its immediate background? After all, the driver's eyesight may be shifted from road surface to surfaces of billboards, shop display windows etc. whose luminance is much higher.

It is a difficult task to find answers to these questions and numerous scientific experiments are still required, but they will surely allow us to assess Visibility Levels matching real road conditions with much higher accuracy.

\section{Limits when applying the STV criterion for purposes of designing road lighting according to European standards and recommendations}

The method of calculating STV as described in the American National Standard Practice for Roadway Lighting [10] makes it possible to assess visibility in a relatively simple, step-by-step method. This method, however, has been created for design purposes based on American standards. The visibility criterion is not used for design purposes in Europe. The research to establish the European concept of visibility is still under way, as the direct takeover of STV as 
employed in USA for European requirements and recommendations is a difficult task. There are several differences between the American [10] and European $[8,11]$ design requirements and recommendations.

The following are some of the more important differences:

- Reflectance and the size of the critical obstacle. The American [10] standard used for calculations identifies the critical obstacle as a flat object with diffuse reflection and reflectance $\rho=50 \%$ and size $18 \mathrm{~cm}$ by $18 \mathrm{~cm}$. The CIE [4] recommended critical obstacle is also a flat object with diffuse reflection, but with reflectance of $\rho=20 \%$, and slightly larger: $20 \mathrm{~cm}$ by $20 \mathrm{~cm}$.

- Computational grid. According to [10], the calculation field is limited by placing two consecutive luminaires in the same row. The location of calculation points in longitudinal direction is equal to $1 / 10$ of the distance between luminaires, but no more than $5 \mathrm{~m}$. The lines of the first and last calculation points in longitudinal direction to the road are located halfway between points in this direction. Crosswise, the points are located on each traffic lane, at a quarter of the width of the lane from each border of the traffic lane. According to $[8,11]$ the computational field is also limited to two consecutive luminaires in one line, and the location of calculation points in longitudinal direction is equal to $1 / 10$ of the distance between luminaires, but no more than $3 \mathrm{~m}$. The first and the last calculation points in longitudinal direction to the road are located halfway between points in this direction. Crosswise, the distance between calculation points is a third of the width of the roadway. The external calculation points are located in the distance of a sixth of the width of the roadway from the edge of the traffic lane.

- Observer's position. American standards assume the altitude of observation at $1.45 \mathrm{~m}$ above the road surface, $83.07 \mathrm{~m}$ before the critical object. The observer are located on each traffic lane, at a quarter of the width of the lane from each border of the traffic lane. The observer's location is subject to change, along with the location of the obstacle in the computational grid. This geometrical array will always generate a single degree observation angle and a fixed angular diameter of the observed critical obstacle of 7.45 minutes. European standards assume the altitude of observation at $1.5 \mathrm{~m}$ above the road surface, $60 \mathrm{~m}$ before the calculation field. The position of the observer in relation to the calculation field is fixed. The observer are located on centre each traffic lane.

- Observer's age. The currently accepted American standard assumes the observer to be 60 years old. For design calculations according to European standards, the observer is usually assumed to be 23 years old.

- Lighting classes and standard requirements with regard to photometric parameters in the road. The lighting requirements specified in American standards are lower in relation to standard values of photometric parameters and refer to a simple classification of roads: class A, freeway class B, expressway, major, collector, local and the possible occurrence of conflict areas with pedestrians. In case of European recommendations, lighting requirements refer to specific lighting classes established on the basis of 
parameters such as: the type of major traffic participants, their typical speed, daily stream of vehicles, complexity of the field of vision, road background luminance.

- Minimal required values of VL. According to [10] the final result of specifying visibility in the road on the basis of STV is the calculation of the weighted average of VL values from all calculation points and its comparison against standard values. Despite the fact that the visibility criterion is not taken into account in Europe for road design, the International Commission on Illumination's publication no. 115 dated 1996 [6] presented suggested values for Visibility Level (VL) for illumination classes from M1 to M5. However, the publication fails to state whether this is a value for a single, specified position of the critical obstacle, or for the assumed computational grid. The publication fails to state whether these are average arithmetic values, weighted average values or perhaps the lowest value of all values calculated for all grid points. The standard minimal STV values and recommended VL values according to [6] are presented in tables 1 and 2 .

Table 1: $\quad$ Lighting requirements based on small target visibility [10].

\begin{tabular}{|c|c|c|c|c|c|}
\hline \multicolumn{2}{|c|}{$\begin{array}{c}\text { Road and Pedestrian } \\
\text { Conflict Area }\end{array}$} & STV Criteria & \multicolumn{3}{|c|}{ Luminance Criteria } \\
\hline \multirow{4}{*}{ Road } & $\begin{array}{c}\text { Pedestria } \\
\text { n Conflict } \\
\text { Area }\end{array}$ & $\begin{array}{c}\text { Weighting } \\
\text { Average VL }\end{array}$ & $\begin{array}{c}\mathrm{L}_{\text {avg }} \\
{\left[\mathrm{cd}^{2} \mathrm{~m}^{2}\right]} \\
\text { Median } \\
<7.3 \mathrm{~m}\end{array}$ & $\begin{array}{c}\mathrm{L}_{\text {avg }} \\
{\left[\mathrm{cd}^{2} / \mathrm{m}^{2}\right.} \\
\text { Median } \\
\geq 7.3 \mathrm{~m}\end{array}$ & $\begin{array}{c}\text { Uniformity } \\
\text { Ratio } \\
\mathrm{L}_{\text {max }} / \mathrm{L}_{\text {min }} \\
\text { (Maximum } \\
\text { Allowed) }\end{array}$ \\
\hline Freeway "A" & - & 3.2 & 0.5 & 0.4 & 6.0 \\
\hline Freeway "B" & - & 2.6 & 0.4 & 0.3 & 6.0 \\
\hline Expressway & - & 3.8 & 0.5 & 0.4 & 6.0 \\
\hline \multirow{4}{*}{ Major } & High & 4.9 & 1.0 & 0.8 & 6.0 \\
\cline { 2 - 6 } & Medium & 4.0 & 0.8 & 0.7 & 6.0 \\
\cline { 2 - 6 } Collector & Low & 3.2 & 0.6 & 0.6 & 6.0 \\
\cline { 2 - 6 } & High & 3.8 & 0.6 & 0.5 & 6.0 \\
\cline { 2 - 6 } & Ledium & 3.2 & 0.5 & 0.4 & 6.0 \\
\hline \multirow{4}{*}{ Local } & High & 2.7 & 0.4 & 0.4 & 6.0 \\
\cline { 2 - 6 } & Medium & 2.2 & 0.5 & 0.4 & 10.0 \\
\cline { 2 - 6 } & Low & 1.6 & 0.3 & 0.3 & 10.0 \\
\hline
\end{tabular}

In the next publication, no. 115 dated 2010 [7], CIE stopped giving VL values until the completion of works of the Technical Committee 4-36. 
Table 2: $\quad$ CIE lighting requirements based on visibility concept [6].

\begin{tabular}{|c|c|c|c|c|}
\hline $\begin{array}{c}\text { LIGHTING } \\
\text { CLASS }\end{array}$ & $\begin{array}{c}\text { VISIBILITY } \\
\text { LEVEL } \\
\text { Minimum } \\
\text { Maintained }\end{array}$ & $\begin{array}{c}\mathrm{L}_{\mathrm{avg}} \\
{\left[\mathrm{cd} / \mathrm{m}^{2}\right]} \\
\text { Minimum } \\
\text { Maintained }\end{array}$ & $\begin{array}{c}\mathrm{L}_{\min } / \mathrm{L}_{\max } \\
\text { Minimum } \\
\text { Maintained }\end{array}$ & $\begin{array}{c}\mathrm{TI} \\
{[\%]} \\
\text { Initial }\end{array}$ \\
\hline M1 & 7.5 & 1.0 & 0.2 & 10 \\
\hline M2 & 7.0 & 1.0 & 0.2 & 10 \\
\hline M3 & 6.0 & 0.7 & 0.2 & 10 \\
\hline M4 & 5.5 & 0.5 & 0.2 & 10 \\
\hline M5 & 5.0 & 0.5 & 0.2 & 10 \\
\hline
\end{tabular}

The differences in assumptions and approach to designing road lighting presented above make it impossible to directly use STV for designing road lighting according to requirements and recommendations in Europe. Naturally, such barriers can be generally overcome with different variables, such as the object's angular diameter or age factor, but it is required to specify appropriate Visibility Level as evaluation criteria, taking into account the differences present between the used standards.

More serious concerns when evaluating the Visibility Level are raised by simplifications assumed for STV, as presented in point 4.

\section{Summary}

The driver's main visual task is to spot objects in the traffic lane or in its background. Road traffic comfort and safety are increased if obstacles are spotted quickly and easily. All over the world, research projects on road visibility are under way. Attempts are made to find answers and clarify doubts, and the results of such research will make it possible to formulate a criterion to evaluate visibility when taking into account conditions which do, in fact, reflect lighting situations and road visibility conditions for drivers.

\section{References}

[1] Adrian, W.: Visibility of targets: model for calculation. Lighting Research and Technology 21/4, pp.181-188, 1989.

[2] Aulthorn E.: Über die Beziehung zwischen Lichtsinn und Sehschärte. Graefes Archiv für Ophthalmologie vol. 167, pp. 4 -75, 1964.

[3] Blackwell H. R.: Contrast Thresholds of the Human Eye. Journal of The Optical Society of America vol. 36, pp. 624-643, 1946

[4] CIE Publication No. 19:1979: A Unified Framework of Methods for Evaluating Visual Performance Aspects of Lighting.

[5] CIE Publication No. 93:1992: Road lighting as an accident countermeasure. 
170 Lighting in Engineering, Architecture and the Environment

[6] CIE Publication No. 115:1995: Recommendations for the lighting of roads for motor and pedestrian traffic.

[7] CIE Publication No. 115:2010: Recommendations for the lighting of roads for motor and pedestrian traffic

[8] CIE Publication No. 140:2000: Road Lighting calculations

[9] CIE Publication No. 146:2002: CIE equations for disability glace

[10] Roadway lighting. ANSI/IESNA RP-8-00: American National Standard Practice for Broadway Lighting, Approval 2000.

[11] PN -EN 13201: 2007: Road lighting, (pol.). 